\title{
Caracterização morfométrica da bacia hidrográfica do rio Tapuio (Ceará-Brasil)
}

Morphometric characterization of the Hydrographic Basin of Rio Tapuio (Ceará - Brazil)

SOUSA $^{1}$, F. R. C. de; PAULA ${ }^{2}$, D. P. de.

rodrigofrcs@hotmail.com

\section{Resumo}

As características físicas de uma bacia hidrográfica como área, perímetro, forma, declividade, comprimento do rio principal e densidade da drenagem exercem importante papel nos processos hidrológicos, atuando sobre o deflúvio, a infiltração, a evapotranspiração e o escoamento superficial e subsuperficial, sendo o conhecimento destas características, essencial para o planejamento ambiental e gestão integrada dos recursos hídricos. Neste sentido, este estudo teve como objetivo compreender o comportamento hidrológico da bacia hidrográfica do rio Tapuio, localizada na porção norte do estado do Ceará (Brasil), através da obtenção e análise das suas características morfométricas por meio de técnicas do geoprocessamento. O levantamento das características morfométricas resultaram em importantes análises, dentre eles, é possível destacar a fator de forma e de compacidade que revelam uma bacia alongada com baixa propensão para enchentes. Outras questões suscitam a necessidade de pesquisas que possam modelar os processos hidrológicos como eventos de chuvas intensas, vazão, escoamento, entre outros.

Palavras-chave: Morfometria, Bacia hidrográfica, Modelagem de sistemas ambientais.

\begin{abstract}
Physical sets of a hydrographic basin such as area, perimeter, shape, declivity, length of the main river and the density of the drainage exercise an important function in hydrological process acting on runoff, percolation, evapotranspiration, surface and subsurface flow, being the knowledge of these characteristics essentials to the environmental planning and the integrated management of hydrological resources. Thus, this study aims understand the hydrous behavior of the hydrographic basin of Rio Tapuio, located in the North of Ceará (Brazil), through obtainment and analysis of morphometric characteristics by techniques of geoprocessing. The research identified the form and Compactness Coefficient of the basin that shows an elongated basin with low propensity for floods. Other questions highlight the necessity of research that can model hydrological process as events of heavy rains, output, outflow and others.
\end{abstract}

Keywords: Morphometry, Hydrographic Basin, Modeling of environmental systems.

\section{INTRODUÇÃO}

A bacia hidrográfica é a unidade físico territorial fundamental para o planejamento ambiental e gerência do território, tendo como foco principal os recursos hídricos (GUERRA e CHUNHA, 2012; NASCIMENTO, 2005; TUCCI, 2001). Esse território geográfico é delimitado pelos divisores de água e integrado pela rede de drenagem, por sua vez, constituída por um rio principal e seus tributários, a bacia hidrográfica possibilita o desenvolvimento de análises multifacetadas compostas tanto por elementos da natureza como da sociedade.

Os estudos em bacias hidrográficas no contexto do semiárido brasileiro são mais relevantes ainda, sobretudo devido à escassez natural dos recursos hídricos que leva à necessidade de diversas práticas de convivência com esta realidade, seja por meio da construção de grandes obras hídricas,

\footnotetext{
${ }^{1}$ Francisco Rodrigo Cunha de Sousa, Mestrado Acadêmico em Geografia, Univ. Estadual Vale do Acaraú, Sobral-CE, Brasil. ${ }^{2}$ Davis Pereira de Paula, Departamento de Geografia, Univ. Estadual do Ceará, Mestrado Acadêmico em Geografia da Univ. Estadual Vale do Acaraú, Fortaleza-CE, Brasil.
} 
como represas ou adutoras, ou através do emprego de técnicas adequadas de produção para a agropecuária local, principal atividade econômica na maioria dos municípios sertanejos do Nordeste do Brasil, inclusive do Ceará. Esta situação reforça, ainda mais, a necessidade de utilização de modelos computacionais e matemáticos capazes de simular os processos hidrológicos e as diversas variáveis que o configuram, a fim de se estabelecer padrões de uso sustentável dos recursos hídricos em regiões onde esse recurso é escasso, como no estado do Ceará.

Foi sob a identificação desta problemática que na década 1940, Robert E. Horton estudou os padrões no desenvolvimento dos cursos hídricos e suas respectivas bacias, utilizando-se de métodos quantitativos que permitiram novas concepções metodológicas para o entendimento da dinâmica interna de bacias hidrográficas, fundando, portanto, os estudos morfométricos, que a partir da década seguinte ganhou força com os trabalhos de Strahler (1952) e Christofoletti (1980).

Dessa forma, o entendimento do comportamento hidrológico da bacia hidrográfica é fundamental para o conhecimento da sua dinâmica interna, devendo sua análise partir do levantamento das suas características morfométricas como área, forma, rede de drenagem, geologia e geomorfologia. Villela e Mattos (1975) ressaltaram que as propriedades físicas de uma bacia hidrográfica permitem uma avaliação do seu comportamento hidrológico, pois a medida que se estabelecem as relações e comparações entre os dados conhecidos é possível determinar de forma indireta diversos parâmetros, que comumente são ignorados ou colocados em segundo plano pela escassez de dados detalhados sobre a área de pesquisa (a bacia hidrográfica do rio Tapuio).

Nesta perspectiva, o objetivo deste estudo compreende o entendimento do comportamento hidrológico da bacia hidrográfica do rio Tapuio (Ceará-Brasil), por meio da obtenção e análise das suas características morfométricas, através do uso de técnicas e metodologias do geoprocessamento.

A bacia hidrográfica do rio Tapuio está inserida no contexto da bacia do rio Coreaú, localizada na porção Noroeste do estado do Ceará, à aproximadamente $380 \mathrm{Km}$ da capital, Fortaleza. O seu principal acesso se dá pela CE-085. Trata-se de uma área de aproximadamente $512,8 \mathrm{Km} 2$ entre as longitudes $41^{\circ} 12^{\prime} 32,04^{\prime \prime} \mathrm{W}$ e $40^{\circ} 56^{\prime} 23,99^{\prime \prime}$ e latitudes $3^{\circ} 16^{\prime} 55,23^{\prime \prime} \mathrm{S}$ e $2^{\circ} 53^{\prime}$ 14,13"S (Figura 1). A bacia em questão apresenta drenagem direta ao Oceano Atlântico, drenando parcialmente a região onde se encontram os Municípios de Camocim, Barroquinha e Granja.

De acordo com a classificação climática de Köppen-Geiger, o clima predominante na região é Equatorial Continental (Af), com precipitações médias anuais acima de $1000 \mathrm{~mm}$, sofrendo influência tanto da sazonalidade do semiárido nordestino como dos ventos alísios do litoral norte cearense. Do ponto de vista morfoestrutural, a bacia hidrográfica está inserida sobretudo nos tabuleiros pré-litoraneos, com caimento topográfico suave, formados no período Plio-Quaternário recoberto por solos do tipo Neossolos e Argissolos, enquanto que na planície litorânea é composta por terrenos recentes, submetidos as influencias marinha, eólica, fluvial e pluvial (SOUZA, 2007). 


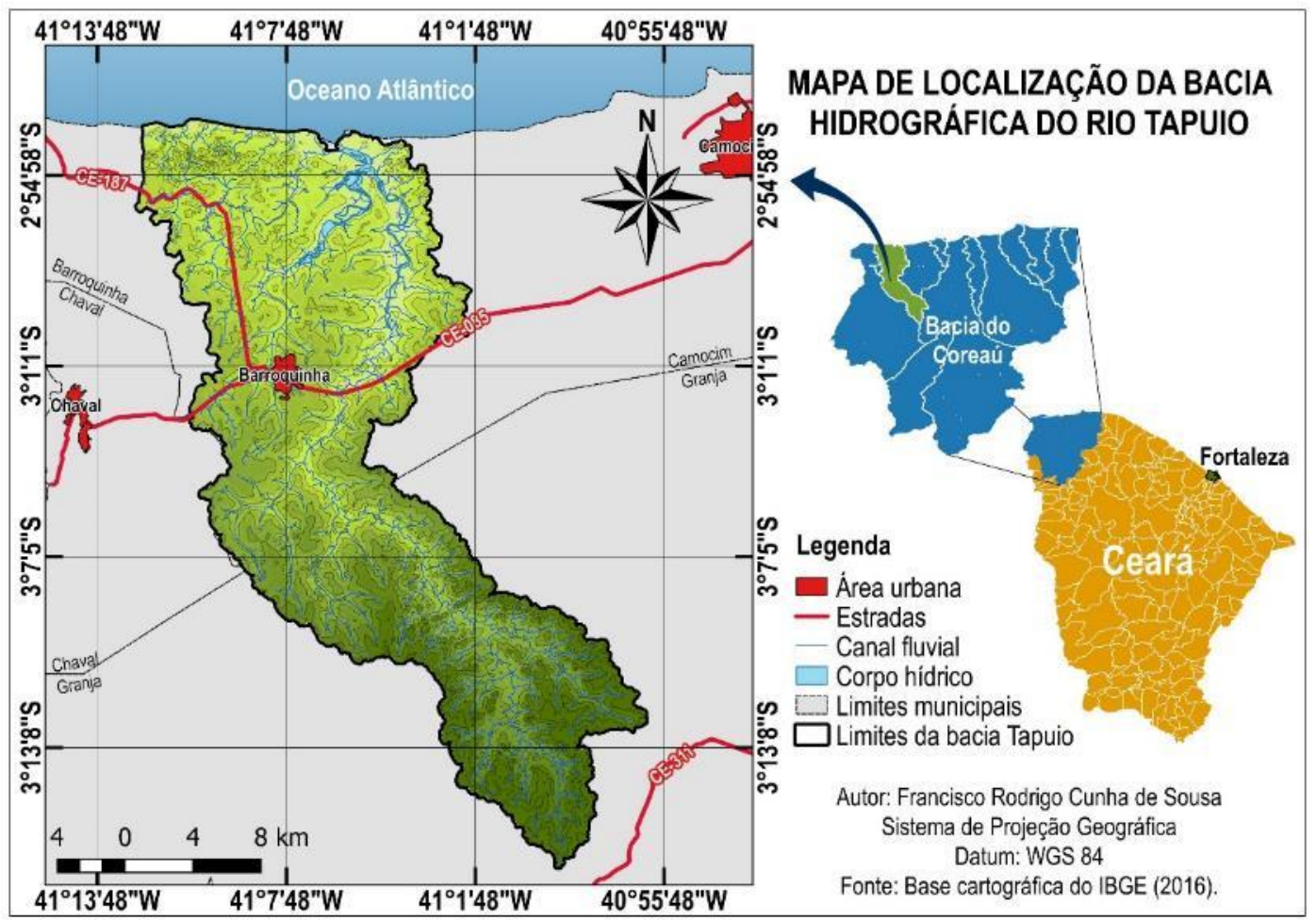

Figura 01. Mapa de localização da bacia hidrográfica do rio Tapuio. Fonte: autores (2016).

\section{METODOLOGIA}

No levantamento dos aspectos fisiográficos e análise morfométrica da bacia hidrográfica, o presente trabalho envolveu as etapas de pesquisa bibliográfica sobre o tema, através da leitura de textos como Villela e Mattos (1975), Coelho-Neto (2009) e Collischonn (2013), por meio das quais foram aplicadas as formulações deste artigo. Procedeu-se ainda com a preparação da base cartográfica da rede de drenagem, pré-processamento e processamento do Modelo Digital de Elevação (MDE) do projeto TOPODATA para a área em estudos.

Os procedimentos operacionais foram realizados com auxílio do software QGIS 2.16, que foi integrado com o SAGA GIS 2.1 e o GRASS GIS 7.0, através de complementos, possibilitando organizar, processar, analisar e interpretar os dados geográficos pertinentes a bacia do rio Tapuio.

Os limites da bacia hidrográfica, bem como a rede de drenagem foram obtidos por meio da ferramenta r.watershed do GRASS GIS, tendo por entrada o MDE e limiares de processamento os valores mínimos de 50.000 e 250 pixels. Por meio da ferramenta r.to.vect procedeu-se com a conversão dos dados para o formato vetorial, que por sua vez permitiu o levantamento das características geométricas da bacia hidrográfica, sejam elas: Área (A); perímetro (P); Coeficiente de compacidade (Kc); Fator de forma (Kf); Índice de circularidade (IC); Padrão de drenagem.

A forma superficial de uma bacia hidrográfica está relacionada ao seu tempo de concentração $(\mathrm{Tc})$, compreendido como o tempo necessário para que a água precipitada na região mais remota da bacia hidrográfica seja transportada pela ação da gravidade até o seu exutório, neste sentido o tempo de concentração é o tempo, contado a partir do início da precipitação, necessário 
para que toda a bacia contribua com a vazão na saída, ocasionando o pico de vazão durante o deflúvio (SILVEIRA, 2005).

O coeficiente de compacidade $(\mathrm{Kc})$, dado pela equação 1 , permite relacionar a forma da bacia com a forma de um círculo, através da comparação entre os perímetros da bacia e o perímetro de uma circunferência, considerando as suas áreas iguais.

$k c=\frac{P}{2 \pi r} \cong 0,28 \cdot \frac{P}{\sqrt{A}}$

Onde $\mathrm{P}$ é o perímetro total da bacia hidrográfica em $\mathrm{Km}$ e A é sua área total em $\mathrm{Km}^{2}$. O coeficiente de compacidade $(\mathrm{Kc})$ é dado por um número adimensional que será maior quanto mais irregular for a forma da bacia e será mais próximo for de 1, quanto mais próximo da forma de um círculo for a forma da bacia (COLLISCHONN, 2013).

Por sua vez, o índice de circularidade (Ic), dado pela equação 2, consiste no parâmetro que relaciona a área total (A) da bacia com a área do círculo (Ac), de perímetro (P) igual ao da bacia hidrográfica. $\mathrm{O}$ valor do $\mathrm{Ic}=0,15$ representa o valor intermediário, valores acima de 0,51 sugerem bacias hidrográficas alongadas, enquanto valores abaixo de 0,51 denotam bacias mais arredondadas. Ic $=\frac{A}{A c}=\frac{\pi r^{2}}{A c} \cong 12,57 \cdot \frac{A}{P^{2}}$

O fator de forma (Kf) é dado pela relação entre a largura média $(\bar{L})$ e o comprimento (L) axial da bacia hidrográfica, sendo a largura média o resultado da divisão da área total (A) pelo comprimento da bacia (L), portanto o fator de forma é dado pela equação 3:

$K f=\frac{\bar{L}}{L}=\frac{A / L}{L}=\frac{A}{L^{2}}$

Assim, quanto menor o fator de forma, significa que mais alongada é a bacia hidrográfica, e que de acordo com Villela e Mattos (1975) caracteriza-a como sendo mais ou menos propícia à ocorrência de enchentes desencadeadas por chuvas intensas, sendo o fator de forma diretamente proporcional a tendência a ocorrência de enchentes, visto que um menor fator de forma representa uma bacia mais alongada que teoricamente, está menos propícia a uma precipitação em toda a sua área simultaneamente, evitando grandes picos de escoamento superficial.

As características do relevo (como orientação das vertentes; altitude mínima, média e máxima; declividade mínima, média e máxima; relação de relevo $(\mathrm{Rr})$ apresentam influência direta sobre os fatores meteorológicos e hidrográficos, pois a medida que as variações na altitude influenciam nas variações de pressão, temperatura e umidade, as variações na declividade estão diretamente relacionadas com a velocidade e o perfil de escoamento superficial da água. Estes parâmetros foram obtidos através das ferramentas de análise de terreno do software Qgis.

A relação de relevo, dada pela equação 4, por sua vez, é resultante da divisão da amplitude altimétrica $(\Delta a)$ pelo comprimento do rio principal (L), permitindo comprovar o quanto o relevo é suave ou ondulado. 
$R r=\frac{\Delta a}{L}$

No que diz respeito às características da rede de drenagem (comprimento do curso d'água principal (L); densidade de drenagem (Dd); índice de sinuosidade (Is); comprimento total dos cursos d'água (Lt); ordem dos cursos de água) é possível destacar que é composta pelo rio principal e seus tributários, pode se afirmar ainda que são importantes parâmetros que permitem compreender o caminho percorrido pela água na bacia hidrográfica.

A ordem dos cursos d’água representa o grau de ramificação ou bifurcações do sistema de drenagem da bacia (TUCCI, 2001) e pode ser determinada seguindo-se os critérios introduzidos por Horton (1945) e posteriormente adaptados por Strahler (1952). Neste estudo, utilizou-se a classificação apresentada por Strahler (1952), que considera como sendo os canais de primeira ordem aqueles que não tem tributários, os canais de segunda ordem são o resultado da junção de dois canais de primeira ordem, os canais de terceira ordem resultam da junção de dois canais de segunda ordem e assim sucessivamente até o exutório da bacia hidrográfica.

A relação entre o comprimento total dos cursos d'água (Lt) de uma bacia e a sua área total (A) representa a densidade da drenagem $(\mathrm{Dd})$, dada na equação 5. Esse valor traduz a relação entre os parâmetros climáticos e o comportamento hidrológico da rocha diante das intempéries.

$D d=\frac{L t}{A}$

O índice de sinuosidade (Is) é obtido através da relação entre o comprimento do canal principal (L) e a distância vetorial entre os extremos do rio principal (Dv), expresso na equação 6. Canais com sinuosidade próximas a 1 são canais retilíneos, enquanto canais com índice de sinuosidade próximos a 2 são canais sinuosos. O índice de sinuosidade é um fator que influencia na velocidade do escoamento superficial e ao mesmo tempo é influenciado pela quantidade de sedimentos que transporta.

$I S=\frac{L}{D v}$

Outras informações como área, perímetro e distâncias foram obtidas pelas calculadoras de campo e raster do software Qgis.

\section{RESULTADOS E DISCUSSÃO}

As características físicas de uma bacia hidrográfica exercem importante papel nos processos hidrológicos, atuando sobre a infiltração, o deflúvio, a evapotranspiração e o escoamento superficial e subsuperficial, de forma que a geologia e a geomorfologia refletem diretamente sobre a quantidade de água que entra na bacia hidrográfica, sobretudo através de precipitações, pois propiciam os divisores de água que limitam e definem o fluxo hídrico e permitem o estabelecimento de um padrão de drenagem, passível de ser identificado, quantificado, classificado e caracterizado. 
$\mathrm{Na}$ análise morfométrica da bacia do rio Tapuio, é possível destacar os seguintes resultados: a bacia hidrográfica possui área de aproximadamente $512,873 \mathrm{Km}^{2}$, com perímetro 181,859 Km (Quadro 1), drenada pelo rio Tapuio - cujo comprimento axial é da ordem de 80,343 $\mathrm{Km}$ - e seus tributários, sendo o rio dos Remédios o principal tributário. Trata-se, portanto, de uma unidade hidrológica de médias dimensões.

\begin{tabular}{|c|c|c|}
\hline \multicolumn{2}{|r|}{ Características morfométricas } & Valores \\
\hline \multirow{5}{*}{ 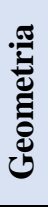 } & Área da drenagem (A) & $512,873 \mathrm{Km}^{2}$ \\
\hline & Perímetro $(\mathrm{P})$ & $181,859 \mathrm{Km}$ \\
\hline & Coeficiente de compacidade (Kc) & 2,248 \\
\hline & Índice de circularidade (Ic) & 0,194 \\
\hline & Fator de forma (Kf) & 0,095 \\
\hline \multirow{7}{*}{ 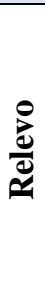 } & Altitude mínima & $0,6 \mathrm{~m}$ \\
\hline & Altitude média & $36,67 \mathrm{~m}$ \\
\hline & Altitude máxima & $105,28 \mathrm{~m}$ \\
\hline & Declividade mínima & $0,140 \%$ \\
\hline & Declividade média & $3,415 \%$ \\
\hline & Declividade máxima & $32,972 \%$ \\
\hline & Relação de relevo (Rr) & 0,0014 \\
\hline \multirow{6}{*}{ 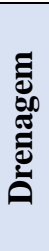 } & Comprimento do rio principal (L) & $73,413 \mathrm{Km}$ \\
\hline & Comprimento total da drenagem (Lt) & $615,549 \mathrm{Km}$ \\
\hline & Densidade da drenagem $(\mathrm{Dd})$ & $1,2002 \mathrm{~km} / \mathrm{km}^{2}$ \\
\hline & Î́ndice de sinuosidade (Is) & 1,655 \\
\hline & Quantidade total de canais de drenagem & 860 \\
\hline & Ordem da bacia & $5^{\mathrm{a}}$ \\
\hline
\end{tabular}

O coeficiente de compacidade (kc) calculado para a bacia do rio Tapuio foi de 2,248, o que permite estimar um longo tempo de concentração da água precipitada no interior da bacia, à medida que este valor está bem acima da unidade, evidenciando o formato alongado da bacia. O baixo índice de circularidade (Ic) de 0,194 para a área, também ratifica o formato alongado da bacia em detrimento à circunferência. A Figura 02 ilustra a relação entre a área da bacia do rio Tapuio e uma circunferência com área equivalente - relação que define o Coeficiente de compacidade (Kc), bem como a relação entre o perímetro da bacia e o perímetro de uma circunferência concêntrica de mesmo perímetro, sendo a relação que define o índice de circularidade (Ic).

$\mathrm{O}$ baixo fator de forma $(\mathrm{Kt})$ que apresenta valor igual a 0,095 reforça ainda mais o formato alongado da bacia. Por outro lado, o fator de forma também permite interpretar a ocorrência de um número significativo de tributários atingindo o rio principal, sobretudo no médio e alto curso, aumentando a taxa de escoamento superficial no baixo curso e consequentemente ocasionando áreas alagadas no baixo curso durante a maior parte do ano.

Estes resultados permitem entender que a forma da bacia, aliada as características meteorológicas da área (marcadas por chuvas convectivas de curta duração e muito concentradas em determinadas áreas), em condições climáticas normais, quase nunca precipitam em toda a bacia hidrográfica ao mesmo tempo, dada sua forma alongada, situação que reforça as pequenas 
probabilidades de ocorrência de enchentes no baixo curso do rio Tapuio e ao mesmo tempo uma baixa concentração de deflúvio (VILLELA E MATTOS, 1975).

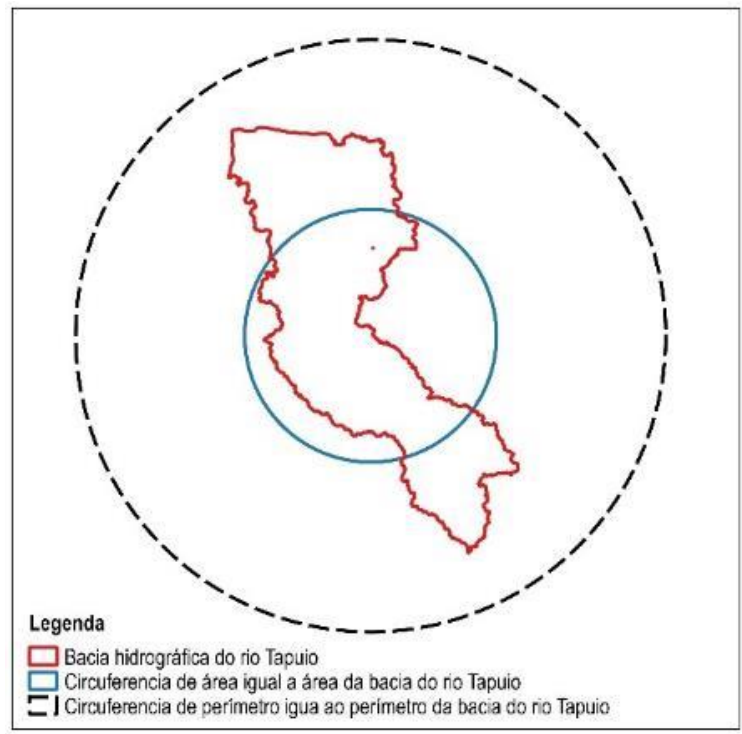

Figura 02. Comparações da forma da bacia com a forma da circunferência. Fonte: autores (2016).

A altitude variou entre $0,6 \mathrm{~m}$ e 105,28 $\mathrm{m}$, sendo $36,67 \mathrm{~m}$ a altitude média dos pixels do Modelo Digital de Elevação para a área da bacia do rio Tapuio. As variações de altitude estão diretamente relacionadas com os parâmetros meteorológicos como a quantidade de luz incidente, temperaturas, pressão e por consequência, a umidade relativa do ar. Além do mais, as variações na altitude também influenciam diretamente no declive do relevo.

A declividade média encontrada na bacia hidrográfica foi de $3,415 \%$, portanto, descritiva de um relevo predominantemente suave-ondulado encontrado na região, enquanto a declividade mínima foi de $0,14 \%$ (relevo plano) e a declividade máxima foi de 32,972 \% (relevo montanhoso). No Figura 3 é apresentado a distribuição da declividade em cinco classes, bem como a sua quantificação (em porcentagem). A relação de relevo (Rr) encontrada foi de 0,0014 , baixo valor que reforça o padrão suave-ondulado, quase plano da bacia hidrográfica do rio Tapuio.

O conhecimento sobre a declividade representa um dos parâmetros mais significativos ao planejamento e gestão de uso dos recursos naturais de uma bacia hidrográfica, à medida que é tocante à relação entre as diversas formas e caminhos que a água pode assumir ao entrar no sistema da bacia hidrográfica, exercendo influência sobre a distribuição da cobertura vegetal, processos erosivos e pedogênicos, exposição à luz solar e interação humana em práticas como a agricultura. Além do mais, a declividade influencia na quantidade e a qualidade da água que é absorvida pelo solo e/ou que é evapotranspirada para a atmosfera ou escoada na rede de drenagem, pois é fator que interfere na velocidade do escoamento e por consequência, na quantidade de infiltração e evapotranspiração, além do aumento no potencial de transporte de sedimento das porções mais elevadas do relevo. 
A densidade de drenagem obtida foi de $1,2002 \mathrm{Km} / \mathrm{Km}^{2}$. Pode-se afirmar que este índice varia de $0,5 \mathrm{Km} / \mathrm{Km}^{2}$, para bacias com drenagem pobre, a 3,5 ou mais, para bacias excepcionalmente bem drenadas" (VILLELA E MATTOS, 1975), apontando, portanto que a bacia do rio Tapuio apresenta baixa capacidade de drenagem, apesar da grande quantidade de ramificações da rede de drenagem (860 segmentos de canais).

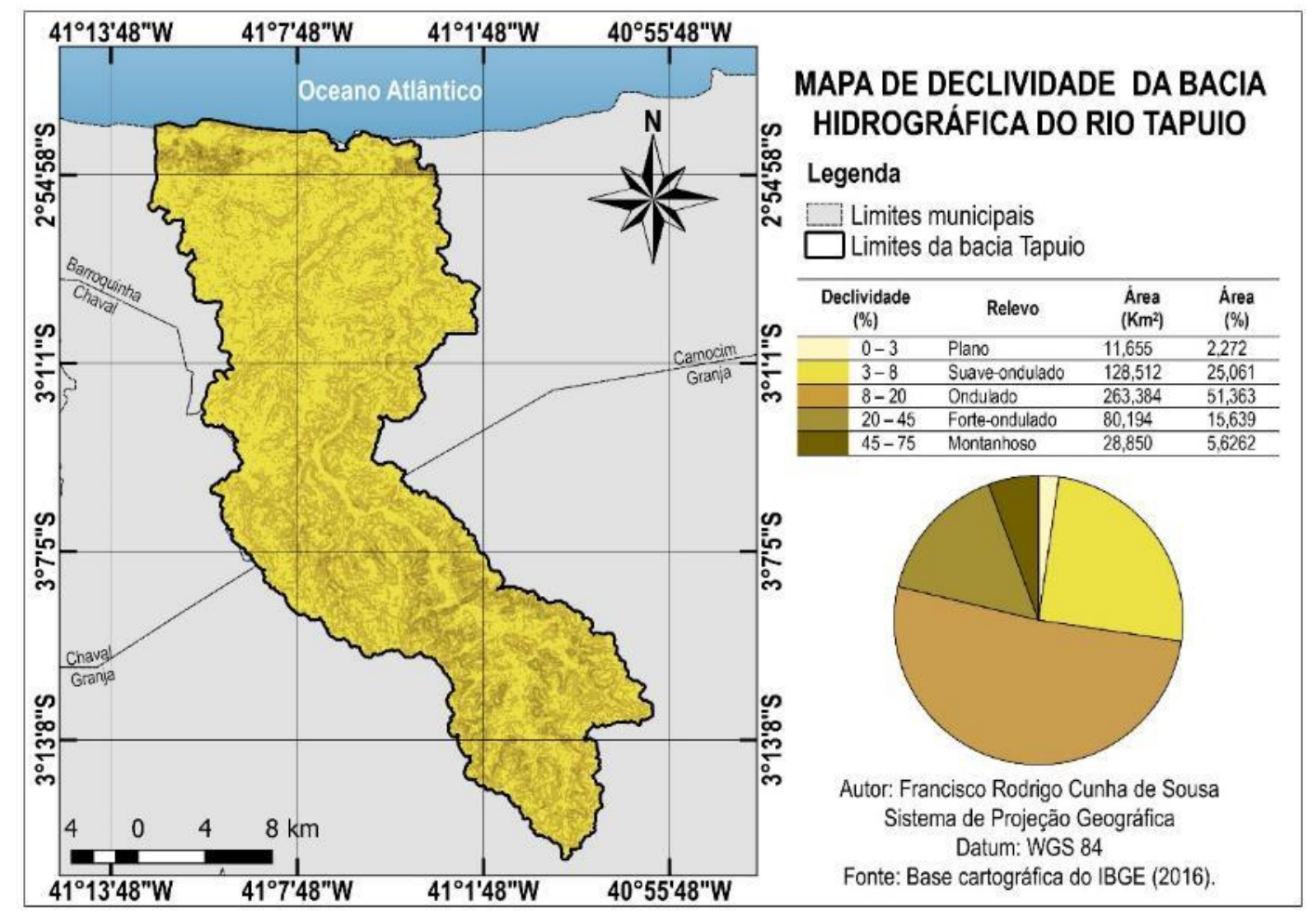

Figura 03. Mapa de declividade da bacia hidrográfica do rio Tapuio. Fonte: autores (2016).

É possível observar que se por um lado a capacidade de drenagem reflete os processos climáticos atuantes na área, por outro ela depende diretamente do comportamento hidrológico da rocha, isso significa que dadas as características do clima semiárido, o baixo valor da densidade da drenagem esclarece a ocorrência de rochas de granulometria grossa, portanto permeáveis e resultantes de processos pedogênicos recentes (na escala geológica) da área pré-litorânea e litorânea cearense. A densidade encontrada, comprova, portanto, os baixos índices de escoamento superficial.

A metodologia proposta por Strahler (1952) para a ordenação de canais revelou que o sistema de drenagem apresenta grau de ramificação de quinta ordem (Figura 4). É importante destacar que a ordem da drenagem está relacionada com o potencial de uso dos recursos naturais de uma bacia hidrográfica, devendo ser um relevante ao planejamento do uso e ocupação, pois considera-se que quanto mais ramificada for a rede de drenagem maior será sua eficiência na integração entre os diversos componentes e processos que ocorrem no interior da bacia hidrográfica.

O índice de sinuosidade de 1,655 obtido para a bacia permite constatar que o rio principal tem sinuosidade de transição, sendo moderadamente tortuoso. A sinuosidade dos canais é influenciada pela carga de sedimentos que são transportados e depositados ao longo do seu curso, 
pela compartimentação litológica, estrutura geológica e declividade da bacia, fato que também reforça a existência dos terrenos geológicos recentes na área, e denotam um período geológico em que o rio está transportando média quantidade de sedimentos, com importante papel na pedogenese.

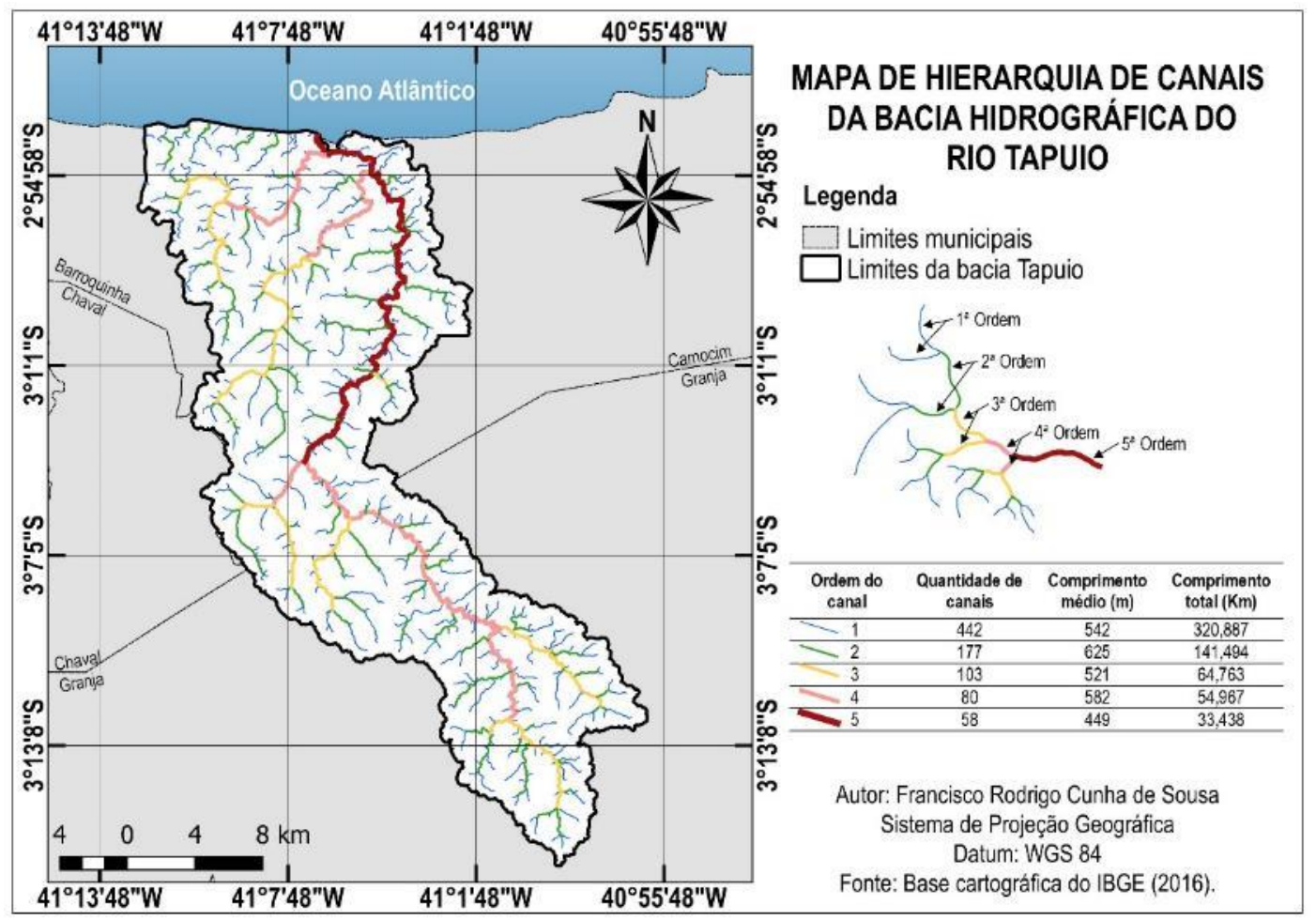

Figura 04. Mapa de hierarquia de canais da bacia hidrográfica do rio Tapuio. Fonte: autores (2016).

\section{CONSIDERAÇÕES FINAIS}

As análises desenvolvidas neste estudo permitem concluir que o levantamento e a interpretação dos dados sobre as características físicas da bacia hidrográfica do rio Tapuio, utilizando-se de modelos quantitativos e técnicas de obtenção de dados a partir do geoprocessamento representam uma etapa inicial e indispensável para o inventário e caracterização dos recursos hídricos da área de pesquisa, permitindo introduzir diversas discussões que envolvem desde a organização e evolução dos processos naturais à ação da sociedade diante do uso e ocupação da bacia hidrográfica.

Os procedimentos adotados na obtenção e tratamento dos dados favoreceram a construção de um conhecimento integrado entre os componentes da natureza, tendo a rede de drenagem como elemento integrador, que permite elencar a ideia de que a construção de análises morfométricas deve ser tida como desafio possível de ser superado com recursos e tecnologias acessíveis.

Por sua vez, os resultados das análises morfométricas demonstraram que a bacia do rio Tapuio apresenta padrão de drenagem dendrítico, com médio grau de ramificação (quinta ordem). O formato alongado da bacia é o principal fator que lhe confere um longo tempo de concentração de deflúvio e baixas probabilidades de enchentes, reforçados pelas baixas declividades da área, que por sua vez também influenciam diretamente na sinuosidade de transição entre o perfil retilíneo e 
anastomosado do rio Tapuio, que atua como importante agente modelador do relevo, transportando grande quantidade de sedimentos das áreas de maior altitude em direção ao oceano e ao mesmo tempo perde vigor no transporte devido as baixas declividades, formando glacis de acumulação.

Os resultados obtidos contribuem como aporte teórico-metodológico com o planejamento ambiental e gestão dos recursos hídricos. Entretanto, para um melhor conhecimento da área de pesquisa, faz-se necessário o desenvolvimento de estudos que possam além da caracterização física da bacia, modelar os processos hidrológicos internos como eventos de chuva, drenagem, vazão, perdas por evapotranspiração, infiltração, escoamento, qualidade e quantidade de água, entre outros.

\section{REFERÊNCIAS}

CHRISTOFOLETTI, A. Geomorfologia. 2. ed. São Paulo: Blucher, 1980.

COELHO NETO, A. L. Hidrologia de encosta na interface com a geomorfologia. In: GUERRA, A. J. T.; CUNHA, S. B. Geomorfologia: uma atualização de bases e conceitos. Rio de Janeiro: Bertrand Brasil, 2009.

COLLISCHONN, W; TASSI, R. Introduzindo hidrologia. Santa Catarina: IPH-UFRS, 2010.

COLLISCHONN, W. Hidrologia para engenharia e ciências ambientais. Porto Alegre: Associação Brasileiras de Recursos Hídricos - ABRH, 2013. 336p.

GUERRA, A. J. T.; CUNHA, S. B. Geomorfologia e meio ambiente. Rio de Janeiro: Bertrand Brasil, 2012.

HORTON, R. E. Erosional development of streams and their drainage basins: hidrophysical approach to quantitative morphology. Geological Society of America Bulletin, v. 56, p. 807-813, 1945.

MATA-LIMA, H. et al. Comportamento hidrológico de bacias hidrográficas: integração de métodos e aplicação a um estudo de caso. Revista Escola de Minas, v. 60, n.3, p. 525-536, 2007.

NASCIMENTO, F. R. et al. Geo-Environmental analysis and identification of degraded areas susceptible to desertification in a semi-arid, tropical ecozone. Rev. Sociedade \& Natureza, Ed. Esp., p. 361-368, 2005.

SAMPAIO, A. C. P; CORDEIRO, A. M. N; BASTOS, F. H. indicadores morfométricos dos processos fluviais no alto curso do rio mundaú, ceará, brasil. Revista GeoUECE. v. 4, n.7. Fortaleza, 2015. p. 64-76. SOUZA, M. J. N. Compartimentação Geoambiental do Ceará. in. BORZACCHIELLO, J. et al. (Orgs.). Ceará: um novo olhar geográfico. Fortaleza: Edições Demócrito Rocha, 2007. p.127-140.

SILVEIRA, A. L. L. Desempenho de Fórmulas de Tempo de Concentração em Bacias Urbanas e Rurais. Revista Brasileira de Recursos hídricos. v. 10. n. 1., 2005. p. 5-23.

STRAHLER, A. Hypsometric (área-altitude) analysis of erosional topography. Geol. Soc. América Bulletin, 1952.

TUCCI, C.E.M. Hidrologia: ciência e aplicação. Porto Alegre: UFRGS/Edusp/ABRH, 2001.

VALERIANO, M. M. Modelo digital de variáveis morfométricas com dados SRTM para o território nacional: o projeto TOPODATA. In: XII Simpósio Brasileiro de Sensoriamento Remoto, 2005, Goiânia.

VILLELA, S. M.; MATTOS, A. Hidrologia aplicada. São Paulo: McGraw-Hill do Brasil,1975.

VITTE, A. C.; GUERRA, A. J. T. (Orgs). Reflexões sobre a Geografia Física no Brasil. 6. ed. Rio de Janeiro: Bertrand Brasil, 2012.

\section{AGRADECIMENTOS}

Ao Mestrado Acadêmico em Geografia da Universidade Estadual Vale do Acaraú, por todo o apoio; e à CAPES, pela concessão da bolsa durante o período de estudos.

Recebido em: 14/08/2016

Aceito para publicação em: 01102016 